DOI: http://dx.doi.org/10.18203/2320-1770.ijrcog20172559

Original Research Article

\title{
Osteoporosis awareness among Indian women
}

\author{
Ayesha $^{1 *}$, Rina Sharma ${ }^{1}$, Yasir Ali Khan ${ }^{2}$
}

\begin{abstract}
${ }^{1}$ Department of Obstetrics and Gynecology, TSM Medical College and Hospital, Amausi, Lucknow, Uttar Pradesh, India

${ }^{2}$ Deparment of Orthopaedics, Era’s Lucknow Medical College, Lucknow, Uttar Pradesh, India
\end{abstract}

Received: 21 May 2017

Accepted: 26 May 2017

\section{*Correspondence:}

Dr. Ayesha,

E-mail: drayesha27@gmail.com

Copyright: () the author(s), publisher and licensee Medip Academy. This is an open-access article distributed under the terms of the Creative Commons Attribution Non-Commercial License, which permits unrestricted non-commercial use, distribution, and reproduction in any medium, provided the original work is properly cited.

\section{ABSTRACT}

Background: Osteoporosis is a major public health problem globally. Despite being a common problem, majority of the women are unaware of it. Awareness varies widely according to the level of education. In present study we have tried to assess the awareness of female patients attending the hospital.

Methods: 100 female patients attending gynae OPD were asked to fill a simple questionnaire after taking informed consent. Age, parity, address, and level of education were noted. Data was analysed statistically by SPSS and level of significance was calculated by Chi square test.

Results: Majority of these women belonged to rural background (85\%) and around $64 \%$ of the women were educated (primary schooling and beyond). About $46 \%$ of the women had some awareness regarding osteoporosis and its prevention. Majority (54\%) were unaware. Level of awareness varied significantly with level of education $(\mathrm{p}=0.006)$. Urban dwellers were more aware about osteoporosis when compared to rural women $(\mathrm{p}=0.004)$.

Conclusions: Overall awareness about osteoporosis is low and here is a need to have community based awareness campaigns regarding osteoporosis. Educational programmes need to target on women coming from rural background and those with low education.

Keywords: Awareness, Indian women, Osteoporosis

\section{INTRODUCTION}

Osteoporosis is a major public health problem globally. It is defined as a skeletal disorder characterized by low bone strength, leading to an increased risk of fragility fractures. ${ }^{1}$ Maximum bone loss occurs in women during perimenopause and menopause. As the prevalence of osteoporosis increases with age, it is estimated that up to $70 \%$ of women over the age 80 years have osteoporosis. $^{2}$ Young Asian women are more susceptible to have bone mineral loss when compared to their western counterparts. It is estimated that around half of osteoporosis cases will occur in Asia by $2050 .^{3}$
Dietary deficiency of calcium and low vitamin D levels (secondary to low sun exposure, inadequate dietary vitamin $\mathrm{D}$ intake, lack of food fortification with vitamin D, pigmented skin, environmental pollution, and traditional dress code) are most important causes of osteoporosis. Around $80 \%$ of urban Indian population has low vitamin D levels. ${ }^{4}$ Other risk factors for osteoporosis include increasing age, female sex, Asian origin, low BMI, malnutrition, drugs like corticosteroids and chronic illness.

Preventive strategies include good diet, calcium and vitamin D supplementation and exercise. Calcium and vitamin D supplements appear to be effective in 
preventing bone loss in women, particularly in postmenopausal and with low habitual $\mathrm{Ca}$ intake (<400mg/day). ${ }^{5-7}$ Despite being a common problem, majority of the women are unaware of it. Awareness varies widely according to the level of education. About $10-15 \%$ of urban population in India is aware of osteoporosis. Awareness is much lower in rural dwellers. One study reveals that most of the people get information about osteoporosis through the television and radio $(55 \%)$ when compared to doctors (approximately 20\%). ${ }^{8}$ In present study we have tried to assess the awareness of female patients attending the hospital.

\section{METHODS}

After taking the ethical clearance, around 100 female patients attending the gynae OPD were enrolled for the study. Informed consent was taken. A simple questionnaire was filled on the spot by the patients. The questions covered were about the risk factors (female sex, increasing age, calcium deficiency, poor sunlight exposure, sedentary life style) and preventive measures (dietary sources of calcium, exercise). Age, parity, address, and level of education were noted. Data was analysed statistically by SPSS and level of significance was calculated by Chi square test.

\section{RESULTS}

In this study, 100 female patients were enrolled. Majority of the women belonged to the age group of 25-35years $(40 \%)$. Majority of these women belonged to rural background $(85 \%)$ and around $64 \%$ of the women were educated (primary schooling and beyond). Demographic data is presented in Table 1.

Table 1: Demographic data.

\begin{tabular}{|ll|}
\hline Parameters & $\mathbf{n = 1 0 0}$ \\
\hline Age & \\
\hline$<25$ & 16 \\
\hline 25-34 years & 40 \\
\hline 35-44 years & 24 \\
\hline$\geq 45$ years & 20 \\
\hline Parity & \\
\hline P0 & 10 \\
\hline P1 & 16 \\
\hline$\geq P 2$ & 74 \\
\hline Education & \\
\hline Educated & 64 \\
\hline Uneducated & 36 \\
\hline Residence & \\
\hline Urban & 15 \\
\hline Rural & 85 \\
\hline
\end{tabular}

About $46 \%$ of the women had some awareness regarding osteoporosis and its prevention. Majority (54\%) were unaware. Level of awareness varied significantly with level of education $(p=0.006)$. Urban dwellers were more aware about osteoporosis when compared to rural women $(\mathrm{p}=0.004)$.

Table 2: Relationship between level of education and awareness of osteoporosis.

\begin{tabular}{|lll|}
\hline Parameters & Aware & Unaware \\
\hline Educated & 36 & 28 \\
\hline Uneducated & 10 & 26 \\
\hline Total & 46 & 54 \\
\hline $\mathrm{p}=0.006$ & & \\
\hline
\end{tabular}

Table 3: Relationship between area of residence and awareness of osteoporosis.

\begin{tabular}{|lll|}
\hline Parameters & Aware & Unaware \\
\hline Urban & 12 & 3 \\
\hline Rural & 34 & 51 \\
\hline Total & 46 & 54 \\
\hline $\mathrm{p}=0.004$ & & \\
\hline
\end{tabular}

\section{DISCUSSION}

In this study level of awareness on osteoporosis was low (46\%). Rural women are more ignorant about the condition (40\% were aware). Educated women have more awareness when compared to uneducated women $(56.25 \%$ vs $27.78 \%)$. In a study on Turkish women, $60.8 \%$ had heard of and $44.9 \%$ had heard the correct definition for osteoporosis. Awareness of osteoporosis was high in younger and high educated women $(\mathrm{p}<0.001)$. Television was the main source of knowledge. ${ }^{9}$ Similar finding were reported by study on middle aged and elderly women in Singapore. ${ }^{10}$

Riaz et al also reported higher knowledge about osteoporosis in educated Pakistani women. ${ }^{11}$ Another study also showed significantly lower awareness in women (aged 16-49 years) belonging to lower socioeconomic and less educated group. Women staying in urban areas had better knowledge about osteoporosis. ${ }^{12}$ This was similar to present finding.

As the incidence of osteoporosis increases with age, there is a need to increase awareness among the women of reproductive age groups through community based educational programmes. These programmes must emphasize on risk factors and preventive measures of osteoporosis. This in long term may help in reducing the incidence of osteoporosis. Studies have shown considerable improvement in osteoporosis awareness post educational stratergies. ${ }^{13,14}$ Healthcare workers must focus more on providing information to rural women.

\section{CONCLUSION}

Rural women have poor knowledge about osteoporosis. Level of education also influences the level of awareness. Knowing the characteristics of the women will help in 
planning of community programmes. This in long term may help in reducing incidence of osteoporosis.

Funding: No funding sources

Conflict of interest: None declared

Ethical approval: The study was approved by the Institutional Ethics Committee

\section{REFERENCES}

1. Consensus A. Consensus development conference: diagnosis, prophylaxis, and treatment of osteoporosis. Am J Med. 1993;94(6):646-50.

2. National Institute of Nutrition. Dietary guidelines for Indians - a manual. Hyderabad, India: Indian Council of Medical Research; 1998.

3. Johnell O, Kanis JA. An estimate of the worldwide prevalence, mortality and disability associated with hip fracture. Osteoporos Int. 2004:15:897-902.

4. Mithal A, Bansal B, Kyer CS, Ebeling P. The AsiaPacific Regional Audit-Epidemiology, costs, and burden of osteoporosis in India 2013: A report of International Osteoporosis Foundation. Indian J Endocr Metab. 2014;18:449-54.

5. Lanham-New SA. Importance of calcium, vitamin D and vitamin $\mathrm{K}$ for osteoporosis prevention and treatment. Proceedings of the Nutrition Society. 2008;67(02):163-76.

6. Prentice A. Diet, nutrition and the prevention of osteoporosis. Public Health Nutr. 2004;7(1A; SPI):227-44.

7. Gutin B, Kasper MJ. Can vigorous exercise play a role in osteoporosis prevention? A review. Osteoporosis Int. 1992;2(2):55-69.
8. Patil SS, Hasamnis AA, Jena S, Rashid AK, Narayan KA. Low awareness of osteoporosis among women attending an urban health centre in Mumbai, Western India. Malas J Public Health Med. 2010;10:6-13.

9. Gemalmaz A, Oge A. Knowledge and awareness about osteoporosis and its related factors among rural Turkish women. Clin Rheumatol. 2008;27(6):723-8.

10. Saw SM, Hong CY, Lee J, Wong ML, Chan MF, Cheng A, et al. Awareness and health beliefs of women towards osteoporosis. Osteoporosis Int. 2003;14(7):595-601.

11. Riaz M, Abid N, Patel M, Tariq M, Khan M, Zuberi L. Knowledge about osteoporosis among healthy women attending a tertiary care hospital. J Pak Med Assoc. 2008;58(4):190-4.

12. Akhtar A, Shahid A, Jamal AR, Naveed MA, Aziz Z, Barkat N, et al. Knowledge about osteoporosis in women of child bearing age (15-49 years) attending Fauji Foundation Hospital Rawalpindi. Pak Armed Forces Med J. 2016;66(4):558-63.

13. Shakil A, Gimpel NE, Rizvi H. Awareness and prevention of osteoporosis among South Asian women. J Comm Health. 2010;35:39.

14. Kasper MJ, Peterson MG, Allegrante JP. The need for comprehensive educational osteoporosis prevention programs for young women: Results from a second osteoporosis prevention survey. Arth Rheum. 2001;45:28-34.

Cite this article as: Ayesha, Sharma R, Khan YA. Osteoporosis awareness among Indian women. Int J Reprod Contracept Obstet Gynecol 2017;6:2822-4. 